Published in Sports Engineering, June 2013; 16(2): 61-70

The final publication is available at link.springer.com

http://link.springer.com/article/10.1007/s12283-013-0114-2

\title{
A mathematical modelling study of an athlete's sprint time when towing a weighted sled
}

Nicholas P. Linthorne

Centre for Sports Medicine and Human Performance, School of Sport and Education, Brunel University, Uxbridge, Middlesex, United Kingdom

Corresponding author:

E-mail_Nick.Linthorne@brunel.ac.uk

Phone $\quad+44(0) 1895266479$

Fax $\quad+44(0) 1895269769$ 


\section{Abstract}

This study used a mathematical model to examine the effects of the sled, the running surface, and the athlete on sprint time when towing a weighted sled. Simulations showed that ratio scaling is an appropriate method of normalising the weight of the sled for athletes of different body size. The relationship between sprint time and the weight of the sled was almost linear, as long as the sled was not excessively heavy. The athlete's sprint time and rate of increase in sprint time were greater on running surfaces with a greater coefficient of friction, and on any given running surface an athlete with a greater power-to-weight ratio had a lower rate of increase in sprint time. The angle of the tow cord did not have a substantial effect on an athlete's sprint time. This greater understanding should help coaches set the training intensity experienced by an athlete when performing a sled-towing exercise.

\section{Introduction}

Towing a weighted sled is an effective training method for developing an athlete's sprinting ability, especially the ability to accelerate rapidly off the mark. Sports in which sled-towing exercises are extensively used include track and field athletics, rugby league, rugby union, American football, Australian rules football, and soccer $[7,11,22]$. When training with a sled, the athlete wears a waist or shoulder harness which is connected to the sled by a cord 2$10 \mathrm{~m}$ long. The sled is designed to slide along the ground on two parallel runners or a flat metal base, and it has a small vertical post onto which weights can be stacked. In a sledtowing exercise the athlete starts from a crouched or standing position and then sprints with maximum effort over a short distance.

When training with a sled the coach will often record the time taken for the athlete to accelerate over a distance of 20 or $30 \mathrm{~m}$. The increase in the athlete's sprint time relative to the time in unloaded sprinting is an indicator of the intensity of the exercise. An athlete's 
sprint time in a sled-towing exercise is determined by (a) the weight of the sled; (b) the coefficient of sliding friction for the sled on the running surface; and (c) the physical characteristics and capabilities of the athlete $[7,16,18]$. However, the precise form of the relationships between these factors and the athlete's sprint time are not well understood. A more comprehensive understanding of these relationships could help the coach set the training intensity experienced by the athlete and so help produce a greater gain from the time spent training.

It is generally recognised that in a sled-towing exercise the load on the athlete arises mainly from the friction force between the base of the sled and the running surface. This force is given by the product of the normal force of the sled and the coefficient of friction of the running surface $[7,16]$. When towing a sled over level ground the normal force of the sled is directly proportional to the weight of the sled, and several studies have shown there is a linear relationship between the athlete's sprint time and the weight of the sled $[16,19,20]$. A simple energy argument suggests that when using a running surface with a higher coefficient of friction, the athlete's sprint time in a sled-towing exercise should be greater because more of the athlete's muscular power is dissipated through sled friction. The friction force in a sled-towing exercise is also expected to be affected by the angle of the towing cord. A tow cord that is angled upwards is expected to reduce the normal reaction force of the sled and hence reduce the magnitude of the sled friction force [10].

Unfortunately, we currently lack detailed empirical data concerning the magnitudes of the effects of the coefficient of friction and cord angle on the athlete's sprint time in a sledtowing exercise. Although Linthorne and Cooper [16] found substantial differences in the athlete's rate of increase in sprint time with increasing sled weight when performing a sledtowing exercise on different running surfaces, it was not clear whether there is a linear relationship between the rate of increase in the athlete's sprint time and the coefficient of 
friction of the running surface. Some practitioners suspect that the effect of the cord angle on the sprint time of the athlete is relatively small, but little quantitative data on this factor are currently available. Also, the relationship between the rate of increase in sprint time with increasing sled weight and the distance over which the athlete is timed in the sled-towing exercise is not currently known.

When training with sled-towing exercises, many coaches normalise the weight of the sled to the athlete's body size by loading the sled to a certain percentage of the athlete's body weight $[1,7]$. However, some studies have found that even when the sled weight is scaled for body weight in this way, athletes can still have substantial differences in their rate of increase in sprint time with increasing sled weight $[16,18]$. Therefore, it is not clear that ratio scaling, where the sled weight is set as a percentage of the athlete's body weight, is the most appropriate method of normalising a sled-towing exercise. Also, results from the study by Martinez-Valencia and colleagues [18] suggest that inter-athlete differences in the rate of increase in sprint time might be due to differences in the athlete's power-to-weight ratio. Therefore, coaches could benefit from knowledge of the strength of the relationship between the rate of increase in sprint time and the athlete's power-to-weight ratio.

The preceding discussion highlights some of the limits to our understanding of the factors that affect the athlete's sprint time in a sled-towing exercise. A promising avenue for addressing this shortfall is through a mathematical modelling study. Several investigators have presented models of sprinting which were based on the muscular power generated by the athlete and the resistive forces acting on the athlete $[2,3,24-26]$. In the study presented here, a mathematical model of sprinting was modified by including the frictional force of the sled as an additional term. A systematic study was then conducted of the effects of the weight of the sled, the coefficient of friction of the running surface, the angle of the tow cord, the athlete's body weight, and the athlete's power-to-weight ratio on the athlete's velocity 
profile and sprint time. The aim was to quantify the form and magnitude of the relationships between these variables and the athlete's sprint time. The predictions from this model were expected to be consistent with existing empirical data from studies of sled-towing exercises.

\section{Methods}

A mathematical model of sled towing was developed that considered the muscular power generated by the athlete and the resistive forces acting on the athlete-sled system [2, 3, 2427]. In this model, the energy required for sprinting is released by chemical conversion in the athlete's muscles. The energy passes through a variety of intermediate stages (including the mechanical work of the muscles, strain energy in the muscles and tendons, and kinetic and potential energy of the limbs and centre of mass), but is ultimately degraded to heat or is accounted for by the external work expended on the centre of mass of the athlete-sled system. The power balance equation for the athlete-sled system is

$$
\eta\left(P_{\text {muscle }}-P_{\text {heat }}\right)=P_{\text {ext }} \text {, }
$$

where $P_{\text {muscle }}$ is the power released by chemical conversion in the athlete's muscles, $P_{\text {heat }}$ is the mechanical power that is degraded to heat, $P_{\text {ext }}$ is the external power expended on the centre of mass of the athlete-sled system, and $\eta$ is the efficiency of converting metabolic energy to external work $[3,23]$.

The power generated by chemical conversion in the athlete's muscles is the sum of the contributions from anaerobic and aerobic metabolism:

$$
P_{\text {muscle }}=P_{\text {anamax }} \exp \left(-t / \tau_{\text {ana }}\right)+P_{\text {aermax }}\left[1-\exp \left(-t / \tau_{\text {aer }}\right)\right],
$$

where $P_{\text {anamax }}$ is the maximum power available from anaerobic metabolism, $P_{\text {aermax }}$ is the steady-state maximum power available from aerobic metabolism, $\tau_{\text {ana }}$ is the time constant for the release of anaerobic energy, and $\tau_{\text {aer }}$ is the time constant for the release of aerobic energy 
$[2,3,24,27]$. Equation 2 expresses the finding that in running the power released by anaerobic metabolism decreases rapidly with time from an initial maximum value, and that the power released by aerobic metabolism slowly increases with time towards a maximum value. In a short-duration sled-towing exercise over $20-50 \mathrm{~m}$, the power generated by the athlete's muscles is expected to be mostly produced through anaerobic metabolism.

A large fraction of the power generated by the athlete's muscles is dissipated as heat. In sprinting, the mechanical power degraded into heat is proportional to the athlete's running velocity, $v$, and so may be expressed as

$$
P_{\text {heat }}=A v \text {, }
$$

where $A$ is the rate of degradation of mechanical energy into heat [4].

In a sled-towing exercise the athlete must overcome the inertia of the athlete-sled system, the friction force acting on the base of the sled, and the aerodynamic drag forces acting on the athlete and sled. The rate of performing external work on the centre of mass of the athlete-sled system is then given by

$$
P_{\text {ext }}=P_{\text {inertia }}+P_{\text {friction }}+P_{\text {drag }}
$$

where $P_{\text {inertia }}$ is the power expended in overcoming the inertia of the athlete-sled system, $P_{\text {friction }}$ is the power expended in overcoming the friction force acting on the sled, and $P_{\text {drag }}$ is the power expended in overcoming aerodynamic drag $[2,24]$. The kinetic energy of the athlete-sled system is given by $K E=1 / 2\left(m+m_{\mathrm{s}}\right) v^{2}$, where $m$ is the mass of the athlete, $m_{\mathrm{s}}$ is the mass of the sled, and $v$ is the velocity of the centre of mass of the athlete-sled system. The rate of change of the kinetic energy of the athlete-sled system (i.e., the power expended in overcoming the inertia of the athlete-sled system, $\left.P_{\text {inertia }}\right)$ is then $d(K E) / d t=\left(m+m_{\mathrm{s}}\right) v(d v / d t)$. The power expended in overcoming the sled friction and aerodynamic drag is given by the product of the force and the velocity of the athlete-sled system. Equation 4 then becomes 


$$
P_{\text {ext }}=\left(m+m_{\mathrm{s}}\right) v\left(\frac{d v}{d t}\right)+F_{\text {friction }} v+F_{\mathrm{drag}} v
$$

where $F_{\text {friction }}$ is the friction force that acts on the base of the sled and $F_{\text {drag }}$ is the aerodynamic drag force acting on the athlete-sled system.

The friction force that acts on the base of the sled is given by $F_{\text {friction }}=\mu N$, where $\mu$ is the coefficient of sliding friction for the sled and running surface and $N$ is the normal reaction force acting on the sled $[10,21]$. The normal reaction force of the sled is not necessarily equal to the weight of the sled $\left(m_{\mathrm{s}} g\right)$. If the cord joining the sled to the athlete makes an upwards angle $\theta$ to the horizontal, the sled will experience an upwards pulling force that reduces the normal reaction force. Applying Newton's second law to the forces acting on the sled in the horizontal and vertical directions as it is being towed by an athlete gives $F \cos \theta-$ $F_{\text {friction }}=m_{\mathrm{s}} a$ and $N+F \sin \theta=m_{\mathrm{s}} g$, where $F$ is force exerted by the athlete on the sled, $m_{\mathrm{s}}$ is the mass of the sled, $a$ is the horizontal acceleration of the sled, and $g$ is the acceleration due to gravity $\left(9.81 \mathrm{~m} / \mathrm{s}^{2}\right)$. Eliminating $F$ and $N$ from these three equations gives an expression for the friction force acting on the sled in terms of the angle of the tow cord;

$$
F_{\text {friction }}=\mu m_{\mathrm{S}}\left(\frac{g \cos \theta-a \sin \theta}{\cos \theta+\mu \sin \theta}\right)
$$

The total aerodynamic drag force acting on the athlete and sled system can be considered as the sum of the aerodynamic drag forces acting on the athlete and on the sled [12];

$$
F_{\text {drag }}=1 / 2 \rho S C_{\mathrm{D}} v^{2}+1 / 2 \rho S_{\mathrm{s}} C_{\mathrm{Ds}} v^{2}
$$

where $\rho$ is the air density, $S$ and $C_{\mathrm{D}}$ are the frontal area and drag coefficient of the athlete, $S_{\mathrm{s}}$ and $C_{\mathrm{Ds}}$ are the frontal area and drag coefficient of the sled, and $v$ is the relative velocity of the athlete and the air. In this model it is assumed that the athlete is sprinting in still air (i.e., no wind). 
The power required to perform an athletic movement is affected by the efficiency of converting metabolic energy to external work [23]. At the start of a sled-towing exercise the efficiency of running is assumed to be about $\eta=0.25$, which is the usual efficiency of a concentric muscle contraction. In this model the efficiency increases linearly with velocity as the sprinting action becomes enhanced by storage and recoil of elastic energy in the athlete's muscles and tendons, eventually reaching a value of about $\eta=0.5$ when sprinting at maximum velocity [3]. Therefore, the efficiency of converting metabolic energy to external work during a sprint is given by

$$
\eta=\eta_{\mathrm{o}}+\frac{\left(\eta_{\max }-\eta_{\mathrm{o}}\right) v}{v_{\max }}
$$

where $v_{\max }$ is the athlete's maximum unloaded running velocity, $\eta_{\mathrm{o}}$ is the efficiency at zero velocity, and $\eta_{\max }$ is the efficiency at maximum velocity.

Combining equations 1-8 gives the equation of motion of the athlete-sled system;

$$
\begin{aligned}
{\left[\eta_{\mathrm{o}}+\right.} & \left.\frac{\left(\eta_{\max }-\eta_{\mathrm{o}}\right) v}{v_{\max }}\right]\left\{\left(\frac{P_{\text {anamax }}}{m}\right) \exp \left(-t / \tau_{\text {ana }}\right)+\left(\frac{P_{\text {aermax }}}{m}\right)\left[1-\exp \left(-t / \tau_{\text {aer }}\right)\right]-\left(\frac{A}{m}\right)\left(\frac{d x}{d t}\right)\right\} \\
& =\left(\frac{m+m_{\mathrm{s}}}{m}\right)\left(\frac{d x}{d t}\right)\left(\frac{d^{2} x}{d t^{2}}\right)+\mu\left(\frac{m_{\mathrm{s}}}{m}\right)\left[\frac{g \cos \theta-\left(\frac{d^{2} x}{d t^{2}}\right) \sin \theta}{\cos \theta+\mu \sin \theta}\right]\left(\frac{d x}{d t}\right)+1 / 2 \rho\left(\frac{S C_{\mathrm{D}}+S_{\mathrm{s}} C_{\mathrm{Ds}}}{m}\right)\left(\frac{d x}{d t}\right)^{3},
\end{aligned}
$$

where $d x / d t$ and $d^{2} x / d t^{2}$ are the first (velocity) and second (acceleration) derivatives of position with respect to time. In this study the maximum power available from anaerobic and aerobic metabolism and the rate of degradation of mechanical energy into heat were normalised with respect to the athlete's body mass (i.e., $P_{\text {anamax }} / m, P_{\text {aermax }} / m$, and $A / m$ ) $[3,23]$.

Equation 9 was solved to obtain curves for the position and velocity of the athlete as a function of time. The equation is non-linear and so was computed using numerical methods that were implemented in a technical computing software package (Mathematica; Wolfram Research, Champaign, IL, USA). A 'standard' athlete and sled system was selected with the following values: $m=70 \mathrm{~kg}$ for the athlete's body mass; $m_{\mathrm{s}} / m=0.1$ for the normalised mass 
of the sled; $P_{\text {anamax }} / m=70 \mathrm{~W} / \mathrm{kg}$ for the normalised maximum power available from anaerobic metabolism; $P_{\text {aermax }} / m=18 \mathrm{~W} / \mathrm{kg}$ for the normalised maximum power available from aerobic metabolism; $A / m=4.0 \mathrm{~W} / \mathrm{kg}$ per $\mathrm{m} / \mathrm{s}$ for the normalised rate of degradation of mechanical energy into heat; $\tau_{\text {ana }}=13 \mathrm{~s}$ and $\tau_{\text {aer }}=25 \mathrm{~s}$ for the rates of release of energy for anaerobic metabolism and aerobic metabolism; $v_{\max }=10 \mathrm{~m} / \mathrm{s}$ for the athlete's maximum unloaded running velocity; $\eta_{\mathrm{o}}=0.25$ for the efficiency at zero velocity; and $\eta_{\max }=0.5$ for the efficiency at maximum velocity [3, 23, 26, 27]. The standard value of the coefficient of friction was $\mu=0.6$ as this value was obtained by Linthorne and Cooper [16] for a steel sled sliding on a Rekortan athletics track, and the standard value of the angle of the tow cord was $\theta=0^{\circ}$ (i.e., horizontal). For the standard athlete towing a sled at sea level we have $\rho=1.225$ $\mathrm{kg} / \mathrm{m}^{3}, S=0.50 \mathrm{~m}^{2}, C_{\mathrm{D}}=0.7, S_{\mathrm{s}}=0.05 \mathrm{~m}^{2}$, and $C_{\mathrm{Ds}}=1.0[15,26]$. The athlete's frontal area $(S)$ was assumed to scale in proportion to $m^{2 / 3}[28]$, and so $S=S_{\mathrm{o}}\left(m / m_{\mathrm{o}}\right)^{2 / 3}$, where $S_{\mathrm{o}}$ and $m_{\mathrm{o}}$ are the frontal area $\left(0.50 \mathrm{~m}^{2}\right)$ and body mass $(70 \mathrm{~kg})$ for the standard athlete.

The mathematical model presented here produced realistic simulations of a short sprint without a sled. In the sprint simulations the athlete accelerated quickly from rest, reached a maximum running velocity after several seconds, and then slowly decelerated as the power generated by the athlete decreased. As expected, an athlete with a greater normalised anaerobic power $\left(P_{\text {anamax }} / m\right)$ had a greater acceleration and a higher top speed. The simulations of sprinting without a sled were in good agreement with published sprint time data for elite sprinters and rugby players (Figure 1). By selecting values of $P_{\text {anamax }} / m$, the model gave a good fit to the velocity profiles of elite male and female 100-m sprinters at the 1997 World Championships in Athletics [14]. The fitted values were $P_{\text {anamax }} / m=90-86$ $\mathrm{W} / \mathrm{kg}$ for the top six male sprinters and $P_{\text {anamax }} / m=77-74 \mathrm{~W} / \mathrm{kg}$ for the top six female sprinters. These values are similar to those obtained by Arsac and Locatelli [3]. The model also gave a good fit to the average velocity profile of $60-\mathrm{m}$ sprints by elite male rugby union 
players presented by Duthie and colleagues [9]. The fitted values were $P_{\text {anamax }} / m=55 \mathrm{~W} / \mathrm{kg}$ for the forwards $(m=107.3 \mathrm{~kg})$ and $P_{\text {anamax }} / m=63 \mathrm{~W} / \mathrm{kg}$ for the backs $(m=84.5 \mathrm{~kg})$. The fitted values for the data from elite sprinters and rugby players suggested that most track and field athletes and field sport athletes would have a normalised maximum anaerobic power of between 40 and $90 \mathrm{~W} / \mathrm{kg}$.

[Insert Figure 1 about here]

In simulating a short sprint, the precise values of the other metabolism variables $\left(P_{\text {aermax }} / m, \tau_{\text {ana }}\right.$, and $\left.\tau_{\text {aer }}\right)$ were not important. A change in $P_{\text {aermax }} / m, \tau_{\text {ana }}$, and $\tau_{\text {aer }}$ of $10 \%$ had little effect on the athlete's velocity profile and changed the athlete's 50-m sprint time from the sprint time calculated with the standard values $(6.11 \mathrm{~s})$ by $0.2 \%, 1.0 \%$, and $0.2 \%$, respectively. Likewise, a $10 \%$ change in the drag area of the athlete and sled $\left(S C_{\mathrm{D}}+S_{\mathrm{s}} C_{\mathrm{Ds}}\right)$ changed the athlete's $50-\mathrm{m}$ sprint time by only $0.4 \%$. The precise values of the variables in the efficiency equation were also not important. A $10 \%$ change in $\eta_{\mathrm{o}}, \eta_{\max }$, and $v_{\max }$ changed the athlete's $50-\mathrm{m}$ sprint time by $0.9 \%, 2.3 \%$, and $1.2 \%$, respectively. The low sensitivity of 50-m sprint time to $v_{\max }$ indicated that in the model it was not essential to adjust $v_{\max }$ to reflect changes in the athlete's maximum anaerobic power, $P_{\text {anamax }} / m$. The precise value of the rate of degradation of mechanical energy into heat was also not particularly important; a $10 \%$ increase in $\mathrm{A} / \mathrm{m}$ increased the athlete's 50 -m sprint time by only $2.9 \%$.

The present study was primarily concerned with investigating the athlete's running velocity and sprint time in a sled-towing exercise. The effects of changes in the sled variables $\left(m_{\mathrm{s}}\right.$ and $\left.\theta\right)$, running surface variables $(\mu)$, and athlete variables $\left(m\right.$ and $\left.P_{\text {anamax }} / m\right)$ on the velocity profile and sprint time of the athlete were systematically investigated. When examining a variable, the other variables were held at their standard values and a set of simulations was performed using a plausible range of values for the variable under investigation (sled mass $m_{\mathrm{s}}=0-50 \%$ body mass; cord angle $\theta=0-40^{\circ}$; coefficient of friction 
$\mu=0-0.8$; body mass $m=40-100 \mathrm{~kg}$; and maximum anaerobic power $P_{\text {anamax }} / m=40-90$

$\mathrm{W} / \mathrm{kg}$ ). A series of simulations were performed within each range of variable values, and for each simulation the athlete's velocity profile was generated and the athlete's time to reach 10 , 20 , and $30 \mathrm{~m}$ was calculated.

\section{Results}

As expected, a greater sled mass produced a less rapid acceleration and a slower maximum velocity (Figure 2a). Most of the effect of the mass of the sled was due to the friction force between the sled and the running surface, rather than due to the inertia of the sled (Figure $2 b$ ).

[Insert Figure 2 about here]

As expected, the athlete's 10-, 20-, and 30-m sprint times increased as the mass of the sled was increased. However, the relationship between sprint time and sled mass was not quite linear; there was a slight increase in the rate of increase in sprint time with increasing sled mass. The general shape of the relationship between sprint time and sled mass was the same at distances of 10,20 , and $30 \mathrm{~m}$; but the longer the sprint distance, the greater the athlete's rate of increase in sprint time with increasing sled mass.

The results from the model confirmed that ratio scaling is an appropriate method of normalising the mass of the sled in a sled-towing exercise. When the sled mass was set as a percentage of the athlete's body mass, changes in the athlete's body mass had almost no effect on the athlete's running velocity and sprint time. Athletes as heavy as $100 \mathrm{~kg}$ and as light as $40 \mathrm{~kg}$ produced a $30-\mathrm{m}$ sprint time that was within $0.01 \mathrm{~s}$ of that for the standard athlete $(m=70 \mathrm{~kg})$. Likewise, only very small differences in sprint time with changes in body mass were observed at distances of 10 and $20 \mathrm{~m}$.

As expected, the coefficient of friction of the running surface produced a strong effect on the athlete's running velocity and sprint time. For any given sled mass, a greater 
coefficient of friction resulted in a slightly reduced rate of acceleration and a slower maximum velocity (Figure 3a). At any given distance, the relationship between the decrease in maximum velocity and the coefficient of friction was nearly linear. Patterns similar to that presented in Figure 3a were evident for any given sled mass.

[Insert Figure 3 about here]

Figure 4a shows the effect of the coefficient of friction on the athlete's 30-m sprint time when towing a sled. A greater coefficient of friction resulted in a slower sprint time, and the relationship between sled mass and the $30-\mathrm{m}$ sprint time was nearly linear when the increase in sprint time from unloaded sprinting was less than about $1.0 \mathrm{~s}$. Patterns similar to that presented in Figure 4a were also evident at distances of 10 and $20 \mathrm{~m}$.

[Insert Figure 4 about here]

As expected, the athlete's sprint time was strongly affected by the athlete's normalised maximum anaerobic power $\left(P_{\text {anamax }} / m\right)$. For any given sled mass, a greater anaerobic power resulted in a greater acceleration and a faster maximum velocity (Figure 3b). Patterns similar to that presented in Figure $3 \mathrm{~b}$ were evident for any given sled mass, but with the maximum velocity achieved by the athlete becoming less as the sled mass was increased.

The greater the athlete's anaerobic power, the faster the athlete's $30-\mathrm{m}$ sprint time (Figure 4b). However, the curves of sprint time versus sled mass were not parallel; the greater the athlete's anaerobic power, the lower the rate of increase in sprint time with increasing sled mass. Patterns similar to that presented in Figures $4 \mathrm{~b}$ were also evident at distances of 10 and $20 \mathrm{~m}$, with the rate of increase in sprint time becoming greater when sprinting over a longer distance.

The angle of the tow cord did not substantially affect the athlete's velocity profile and hence had little effect on the athlete's 30-m sprint time (Figure 3c and 4c). For example, when towing a sled at $10 \%$ of body mass, a change in the angle of the tow cord from $0^{\circ}$ to 
$20^{\circ}$ reduced the athlete's $30-\mathrm{m}$ sprint time by only $0.08 \mathrm{~s}$. Patterns similar to that presented in Figure 4c were also evident at distances of 10 and $20 \mathrm{~m}$, with the effect of the cord angle becoming greater when sprinting over a longer distance.

As mentioned previously, the athlete's sprint time increased almost linearly with increasing sled mass, as long as the mass of the sled was not too great. For the standard value of the coefficient of friction $(\mu=0.6)$, the linear region corresponded to when the sled mass was less than about $20 \%$ of the athlete's body mass. The average rate of increase in sprint time when the sled mass was between 0 and $10 \%$ of body mass was calculated and taken as representative of the rate of increase in sprint time in the linear region. The model indicated that the athlete's rate of increase in 30-m sprint time steadily increased with increasing coefficient of friction, and the greater the athlete's anaerobic power $\left(P_{\text {anamax }} / m\right)$ the lesser the effect of the coefficient of friction (Figure 5). Patterns similar to that presented in Figure 5 were also evident at distances of $10 \mathrm{~m}$ and $20 \mathrm{~m}$, with the effect of the coefficient of friction becoming greater when sprinting over a longer distance.

[Insert Figure 5 about here]

As was mentioned previously, the magnitude of the effects of the sled mass, the coefficient of friction, and the athlete's anaerobic power on the athlete's sprint time depended on the sprint distance (e.g., 10, 20, and $30 \mathrm{~m}$ ). The model indicated a near-linear relationship between the athlete's rate of increase in sprint time and the sprint distance, and at any given distance the rate of increase in sprint time was substantially greater for an athlete with a lower anaerobic power (Figure 6).

[Insert Figure 6 about here]

\section{Discussion}


The mathematical model of sled towing showed that an athlete's velocity profile and sprint time are strongly influenced by the mass of the sled, the coefficient of friction of the running surface, and the athlete's maximum anaerobic power (Figures 2, 3, and 4). The model showed that an athlete's sprint time increases almost linearly with increasing sled mass, as long as the mass of the sled is not excessive (Figure 4b). A greater coefficient of friction produces a greater rate of increase in sprint time with increasing sled mass (Figure 5), as does conducting the sled-towing exercise over a greater distance (Figure 6). On any given running surface the rate of increase in sprint time with increasing sled mass depends strongly on the athlete's normalised maximum anaerobic power (Figure 4b). However, the angle of the tow cord does not have a substantial effect on an athlete's sprint time (Figure 4c).

\subsection{Scaling of sled mass}

When using sled-towing exercises, many coaches set the mass of the sled to a percentage of the athlete's body mass (i.e., ratio scaling) so as to account for differences in body size. The findings from the present study support this practice. When the sled mass was normalised to the athlete's body mass, the athlete's velocity profile and the relationship between sprint time and sled mass were essentially independent of the athlete's body mass. We can see how this result arose by re-writing the equation of motion (Equation 9) to give an expression for the acceleration of the athlete-sled system;

$$
\frac{d^{2} x}{d t^{2}}=\frac{\left[\eta_{\mathrm{o}}+\frac{\left(\eta_{\max }-\eta_{\mathrm{o}}\right) v}{\nu_{\max }}\right]\left\{\left(\frac{P_{\text {anamax }}}{m}\right) \exp \left(-t / \tau_{\text {ana }}\right)+\left(\frac{P_{\text {aemax }}}{m}\right)\left[1-\exp \left(-t / \tau_{\text {aer }}\right)\right]-\left(\frac{A}{m}\right)\left(\frac{d x}{d t}\right)\right\}-\mu g\left(\frac{m_{\mathrm{s}}}{m}\right)\left(\frac{d x}{d t}\right)}{\left(1+\frac{m_{\mathrm{s}}}{m}\right)\left(\frac{d x}{d t}\right)} .
$$

Here, the sled-towing model has been simplified slightly by ignoring the effects of aerodynamic drag and by restricting the consideration to that of a horizontal tow cord $(\theta=$ $0^{\circ}$ ). Note that the friction term and the denominator in Equation 10 are proportional to $m_{\mathrm{s}} / m$. Therefore, if the sled mass is scaled in proportion to the athlete's body mass (i.e., $m_{\mathrm{s}} / m$ is held 
constant), then the velocity-time curves of the athlete-sled system are identical for all values of the athlete's body mass. When using the full model (equation 9), small differences in sprint time for athletes of different body mass arise because the aerodynamic drag and the reduction in frictional force due to the angle of the tow cord are not independent of body mass.

In the preceding discussion it was assumed that the athlete's maximum anaerobic power $\left(P_{\text {anamax }}\right)$, maximum aerobic power $\left(P_{\text {aermax }}\right)$, and rate of degradation of mechanical energy into heat $(A)$ should be normalised by dividing by the athlete's body mass. That is, it was assumed that unloaded sprint time is independent of body mass. However, there are sound theoretical arguments and considerable empirical data to support the independence of sprint time and body mass $[6,13,17]$. In the preceding discussion it was also assumed that the metabolism time constants $\left(\tau_{\text {ana }}\right.$ and $\left.\tau_{\text {aer }}\right)$ and the variables in the efficiency equation $\left(v_{\max }\right.$, $\eta_{\mathrm{o}}$, and $\left.\eta_{\max }\right)$ do not depend on the athlete's body mass. However, the effects of these variables on sprint time are relatively small and so any body mass dependence of these variables is not likely to produce a noticeable effect in a sled-towing exercise.

\subsection{Comparison to empirical data}

Empirical data from previous studies of sled-towing exercises support some of the results obtained with the mathematical model. The results from the mathematical model indicate that an athlete's sprint time (over a given distance) should increase almost linearly with increasing sled mass (Figure 4). Linthorne and Cooper [16] examined the effect of sled mass ( 7 loads of up to $30 \%$ of body mass) on the $30-\mathrm{m}$ sprint times of rugby players when running on different types of sports surfaces. For almost all of the 24 combinations of six athletes and four sports surfaces that were used in the study, a linear fit to the athlete's $30-\mathrm{m}$ sprint times was better than a quadratic fit. Martinez-Valencia and colleagues [18] reached a similar 
conclusion when examining the effect of sled mass (4 loads of up to $20 \%$ of body mass) on the 20- and 30-m sprint times of eight sprinters when running on a Mondo athletics track. Murray and colleagues [20] examined the effect of sled mass ( 7 loads of up to $30 \%$ of body mass) on the 10- and 20-m sprint times of 13 rugby players and 20 football players. They did not report the results for each of the 33 athletes individually, but for the mean 10- and $20-\mathrm{m}$ sprint times a linear fit was better than a quadratic fit.

The results from the mathematical model indicate that the rate of increase in sprint time (with increasing sled mass) should steadily increase as the sprint distance is increased (Figure 6). In the study by Murray and colleagues [20], the mean rate of increase in sprint time at 20 $\mathrm{m}(2.8 \mathrm{~s}$ per body mass) was double that at $10 \mathrm{~m}(1.4 \mathrm{~s}$ per body mass $)$, which is in good agreement with the ratio obtained from the mathematical model. Unfortunately, Murray and colleagues did not report the coefficient of friction for the sled-surface combination that was used in their study, and so the magnitudes of the rates of increase in sprint time cannot be readily compared to those of the model.

The results from the mathematical model indicate that an athlete's rate of increase in sprint time (with increasing sled mass) should steadily increase as the coefficient of friction of the running surface is increased (Figure 4a). In a study of sports surfaces by Linthorne and Cooper [16], the mean rate of increase in 30-m sprint time for a Rekortan athletics track (4.6 s per body mass) and an artificial grass hockey pitch (1.9 s per body mass) were consistent with the coefficients of friction of the two surfaces $(\mu=0.58$ and $\mu=0.21)$.

The results from the mathematical model indicate that in a study of sled towing (with a load at a constant percentage of body mass), we would expect to see substantial inter-athlete differences in the rate of increase in sprint times due to differences in the athlete's normalised anaerobic power $\left(P_{\text {anamax }} / m\right)$ (Figure $\left.4 b\right)$. Linthorne and Cooper [16] observed a range of 3.7-5.7 s per body mass for 30-m sprints on a Rekortan athletics track $(\mu=0.58)$. This result 
suggests that the anaerobic power of the athletes in their study were between about 55 and 80 $\mathrm{W} / \mathrm{kg}$ (Figure 5), which is roughly consistent with the values expected for male rugby players. The results from the mathematical model also indicate that we should expect to see greater inter-athlete differences in the rate of increase in sprint times when running on a surface with a higher coefficient of friction (Figure 5). The data reported by Linthorne and Cooper [16] are consistent with the model. They observed a standard deviation in the rate of increase in sprint time among the athletes of $0.71 \mathrm{~s}$ per body mass on a Rekortan athletics track $(\mu=0.58)$, and a correspondingly lower standard deviation of $0.45 \mathrm{~s}$ per body mass on an artificial grass hockey pitch $(\mu=0.21)$.

The results from the mathematical model indicate that an athlete's rate of increase in sprint time (with increasing sled mass) should decrease as the angle of the tow cord is increased (Figure 4c). Barnard [5] examined the effect of changing the tow cord angle on two experienced male sprinters when towing a sled on a Rekortan athletics track. The coefficient of friction for the sled-surface combination was $\mu=0.58$, the sled was loaded to $10 \%$ of the athlete's body mass, and the angle of the tow cord was varied between $4^{\circ}$ and $15^{\circ}$. The $20-\mathrm{m}$ sprint times of the two athletes decreased at a rate of about 0.007 and $0.010 \mathrm{~s}$ per degree increase in tow cord angle, which is about three times greater than that predicted by the model $(0.0027 \mathrm{~s}$ per degree $)$ with the standard athlete and sled values $\left(P_{\text {anamax }} / m=70\right.$ $\mathrm{W} / \mathrm{kg}, m=70 \mathrm{~kg}, m_{\mathrm{s}} / m=0.1$, and $\left.\mu=0.6\right)$. The discrepancy might be because the sledtowing model only accounted for the horizontal force exerted by the sled on the athlete. An upward-angled tow cord will also produce a downward force on the athlete. This downward force might produce an effect on the athlete that is similar to that of a weight belt, and hence further reduce the athlete's sprint time [8].

The mathematical model of a sled-towing exercise presented here could be evaluated in greater detail through obtaining an extensive set of verification data. For example, the model 
predictions of the shape of the athlete's velocity profile and the effects of changes in sled mass, coefficient of friction, and the athlete's anaerobic power on this profile could be compared to such data (Figures 2, 3, and 4). To evaluate these aspects of the model, velocity profile data during a sled-towing exercise could be obtained with a laser gun or radar gun [14]. Analysis of the velocity profile of an unloaded sprint would allow the athlete's maximum anaerobic power $\left(P_{\text {anamax }} / m\right)$ to be estimated, and this value would be useful in evaluating the effects of inter-athlete differences in anaerobic power on the velocity profile in a sled-towing exercise.

\section{Conclusion}

This study used a mathematical model of sled towing that included the anaerobic and aerobic muscular power generated by the athlete and the resistive friction force that acts on the base of the sled. Simulations with the model confirmed that ratio scaling, where the sled weight is set as a percentage of the athlete's body weight, is an appropriate method of normalisation for a sled-towing exercise. For the most common values of sled and athlete variables there was an almost linear increase in the athlete's sprint time as the weight of the sled was increased. The rate of increase in sprint time with increasing sled weight was greater as the distance of the sled-towing exercise was increased. On running surfaces with a greater coefficient of friction the athlete's sprint time and rate of increase in sprint time were greater, and on any given running surface an athlete with a greater power-to-weight ratio had a lower rate of increase in sprint time. The angle of the tow cord did not have a substantial effect on an athlete's sprint time. This greater understanding could help coaches set the training intensity experienced by their athletes and so help produce a greater gain from the time spent training.

\section{Conflict of Interests}


The author declares that he has no conflicts of interest concerning this article.

\section{References}

1. Alcaraz PE, Palao JM, Elvira JLL, Linthorne NP (2008) Effects of three types of resisted sprint training devices on the kinematics of sprinting at maximum velocity. $\mathrm{J}$ Strength Cond Res 22:890-897. doi: 10.1519/JSC.0b013e31816611ea

2. Arsac LM (2002) Effects of altitude on the energetics of human best performances in 100 m running: a theoretical analysis. Eur J Appl Physiol 87:78-84. doi: $10.1007 / \mathrm{s} 00421-002-0587-3$

3. Arsac LM, Locatelli E (2002) Modelling the energetics of 100-m running by using speed curves of world champions. J Appl Physiol 92:1781-1788. doi: 10.1152/japplphysiol.00754.2001

4. Åstrand P-O, Rodahl K, Dahl HA, Strømma SB (2003) Textbook of work physiology: physiological bases of exercise, 4th edn. Human Kinetics, Champaign, IL

5. Barnard S (2011) The effects of varying the length of tow rope during sled towing on sprint performance and joint kinematics in the acceleration phase. Dissertation, Brunel University

6. Crewther BT, McGuigan MR, Gill ND (2011) The ratio and allometric scaling of speed, power, and strength in elite male rugby union players. J Strength Cond Res 25:19681975. doi: 10.1519/JSC.0b013e3181e4f77c

7. Cronin J, Hansen K (2006) Resistance sprint training for the acceleration phase in sprinting. Strength Cond J 28(4):42-51 
8. Cronin J, Hansen K, Kawamori N, McNair P (2008) Effects of weighted vests and sled towing on sprint kinematics. Sports Biomech 7:160-172. doi: $10.1080 / 14763140701841381$

9. Duthie GM, Pyne DP, Marsh DJ, Hooper SL (2006) Sprint patterns in rugby union players during competition. J Strength Cond Res 20:208-214. doi: 10.1519/R-16784.1

10. Halliday D, Resnick R, Walker J (2010) Fundamentals of physics, 9th edn. John Wiley, Hoboken, NJ

11. Harrison AJ, Bourke G (2009) The effect of resisted sprint training on speed and strength performance in male rugby players. J Strength Cond Res 23:275-283. doi: 10.1519/JSC.0b013e318196b81f

12. Hay JG (1993) The biomechanics of sports techniques, 4th edn. Prentice-Hall, Englewood Cliffs, NJ

13. Jaric S, Mirkov D, Markovic G (2005) Normalizing physical performance tests for body size: a proposal for standardization. J Strength Cond Res 19:467-474. doi: 10.1519/R15064.1

14. Kersting UG (1999) Biomechanical analysis of the sprinting events. In: Brüggemann G-P, Koszewski D, Müller H (eds) Biomechanical research project Athens 1997: final report. Meyer and Meyer Sport, Oxford, pp 12-61

15. Linthorne NP (1994) The effect of wind on 100-m sprint times. J Appl Biomech 10:110-131.

16. Linthorne NP, Cooper JE (2012) Effect of the coefficient of friction of a running surface on sprint time in a sled-towing exercise. Sports Biomech 12:175-185. doi: $10.1080 / 14763141.2012 .726638$ 
17. Markovic G, Jaric S (2004) Movement performance and body size: the relationship for different groups of tests. Eur J Appl Physiol 92:139-149. doi: 10.1007/s00421-004$1076-7$

18. Martinez-Valencia MA, Linthorne NP, Alcaraz Ramón PE (2013) Effect of lower body explosive power on sprint time in a sled-towing exercise. Sci Sports (in press)

19. Maulder PS, Bradshaw EJ, Keogh JWL (2008) Kinematic alterations due to different loading schemes in early acceleration sprint performance from starting blocks. $\mathrm{J}$ Strength Cond Res 22:1992-2002. doi: 10.1519/JSC.0b013e31818746fe

20. Murray A, Aitchison TC, Ross G, Sutherland K, Watt I, McLean D, Grant S (2005) The effect of towing a range of relative resistances on sprint performance. J Sports Sci 23:927-935. doi: 10.1080/02640410400023332

21. Persson BNJ (1998) Sliding friction: physical principles and applications, 2nd edn. Springer, Berlin

22. Spinks CD, Murphy AJ, Spinks WL, Lockie RG (2007) The effects of resisted sprint training on acceleration performance and kinematics in soccer, rugby union, and Australian football players. J Strength Cond Res 21:77-85. doi: 10.1519/00124278200702000-00015

23. Van Ingen Schenau GJ, Jacobs R, de Koning JJ (1991) Can cycle power predict sprint running performance? Eur J Appl Physiol 63:255-260. doi: 10.1007/BF00233857

24. Ward-Smith AJ (1984) Air resistance and its influence on the biomechanics and energetics of sprinting at sea level and at altitude. J Biomech 17:339-347. doi: $10.1016 / 0021-9290(84) 90028-9$

25. Ward-Smith AJ (1985) A mathematical theory of running, based on the first law of thermodynamics, and its application to the performance of world-class athletes. $\mathrm{J}$ Biomech 18:337-349. doi: 10.1016/0021-9290(85)90289-1 
26. Ward-Smith AJ (1999) New insights into the effect of wind assistance on sprinting performance. J Sports Sci 17:325-334. doi: 10.1080/026404199366037

27. Ward-Smith AJ, Radford PF (2000) Investigation of the kinetics of anaerobic metabolism by analysis of the performance of elite sprinters. J Biomech 33:997-1004. doi: 10.1016/S0021-9290(00)00035-X

28. Zatsiorsky VM (2006) Science and practice of strength training, 2nd edn. Human Kinetics, Champaign, IL 


\section{Figures}

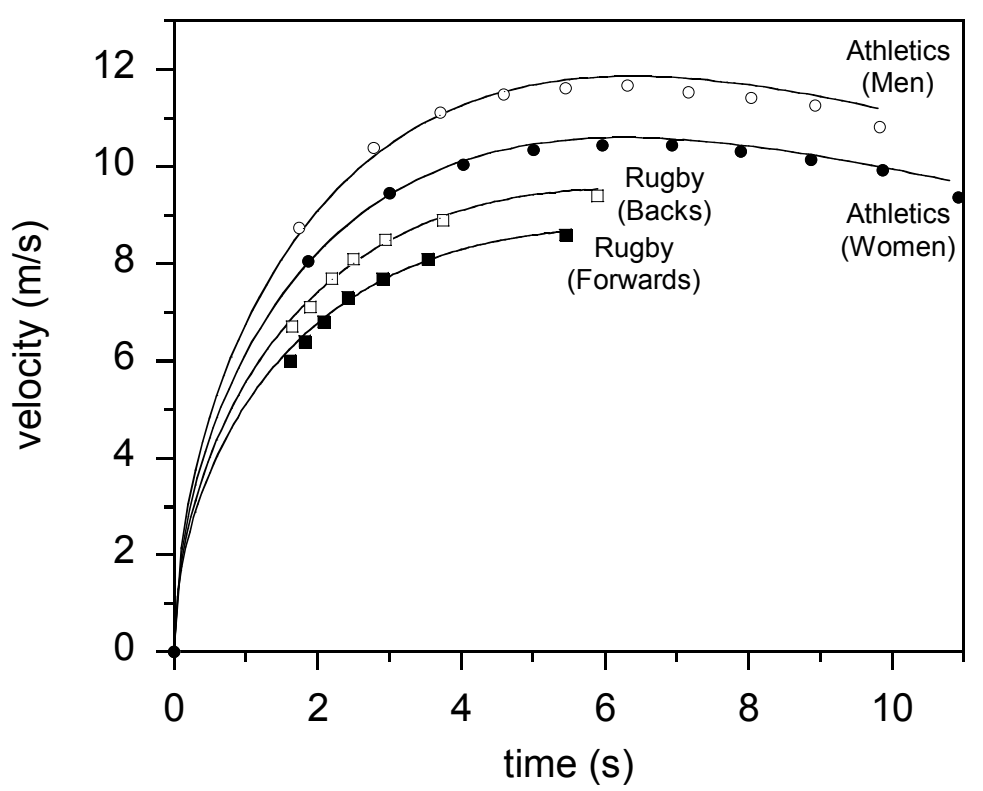

Fig. 1 This plot shows that the sprinting model (with no sled) produced a good fit to data from elite sprinters and rugby players. Data from Kersting [14] are the mean values of the top six place-getters in the men's and women's 100-m competitions at the Athens 1997 World Championships in Athletics, and data from Duthie and colleagues [9] are the mean values for the forwards and backs in 60 -m sprints by elite male rugby union players 


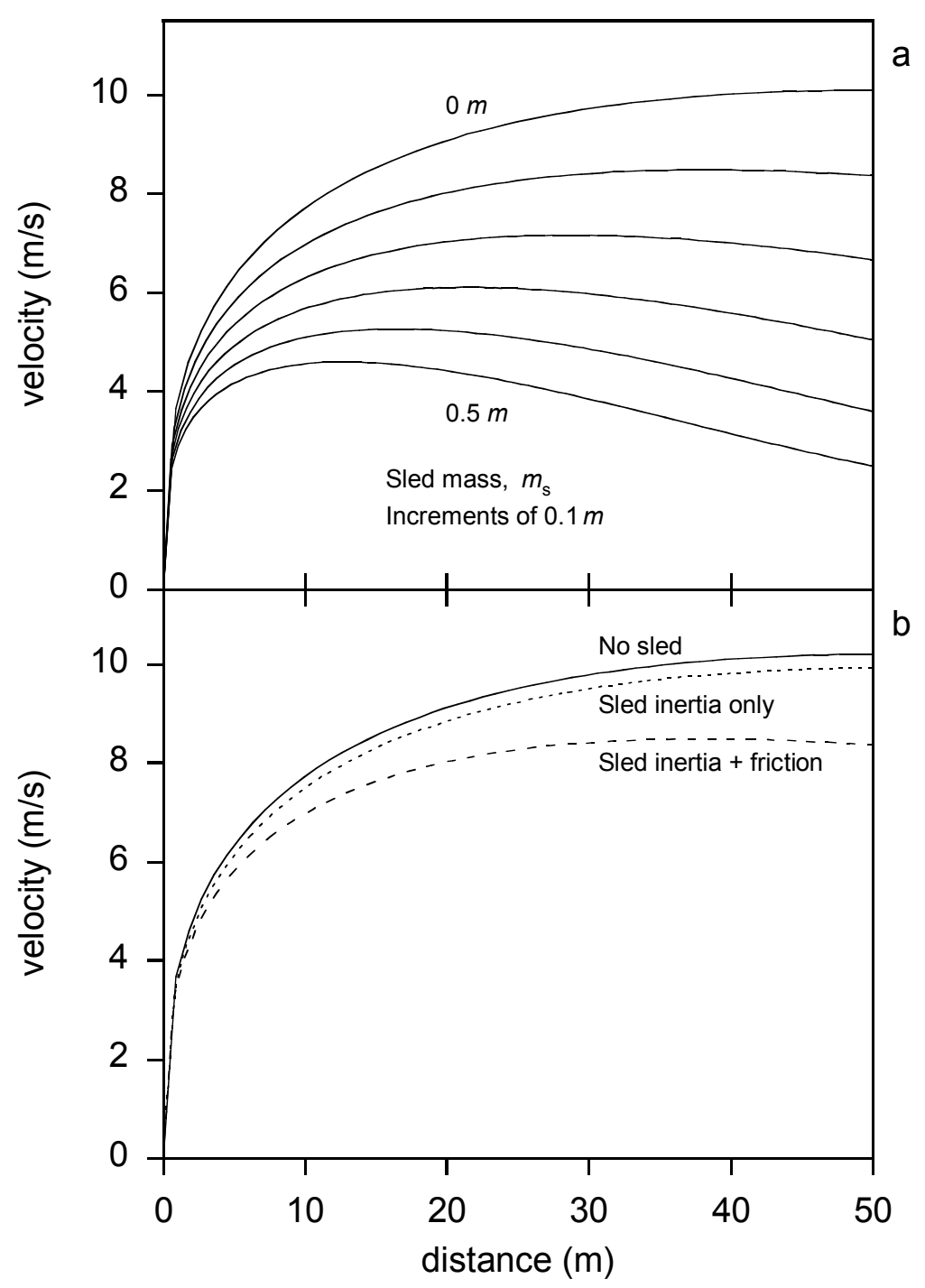

Fig. 2 Plot (a) shows the effect of the mass of the sled $\left(m_{\mathrm{s}}\right)$ on an athlete's velocity profile when towing a weighted sled. Calculations are for a standard athlete with $P_{\text {anamax }} / m=70$ $\mathrm{W} / \mathrm{kg}, m=70 \mathrm{~kg}, \mu=0.6$, and $\theta=0^{\circ}$. The main effects of a heavier sled are to reduce the maximum velocity attained by the athlete and to reduce the distance at which the athlete begins to slow down. Plot (b) shows the relative contributions of sled inertia and sled friction to the athlete's velocity profile: no sled (solid line); sled inertia only (short-dash line); and sled inertia and sled friction (long-dash line). Calculations are for a standard athlete with $P_{\text {anamax }} / m=70 \mathrm{~W} / \mathrm{kg}, m=70 \mathrm{~kg}, m_{\mathrm{s}} / m=0.1, \mu=0.6$, and $\theta=0^{\circ}$. In a sled-towing exercise 
most of the effect of the sled is usually due to the friction force between the base of the sled and the running surface, rather than due to the inertia of the sled 


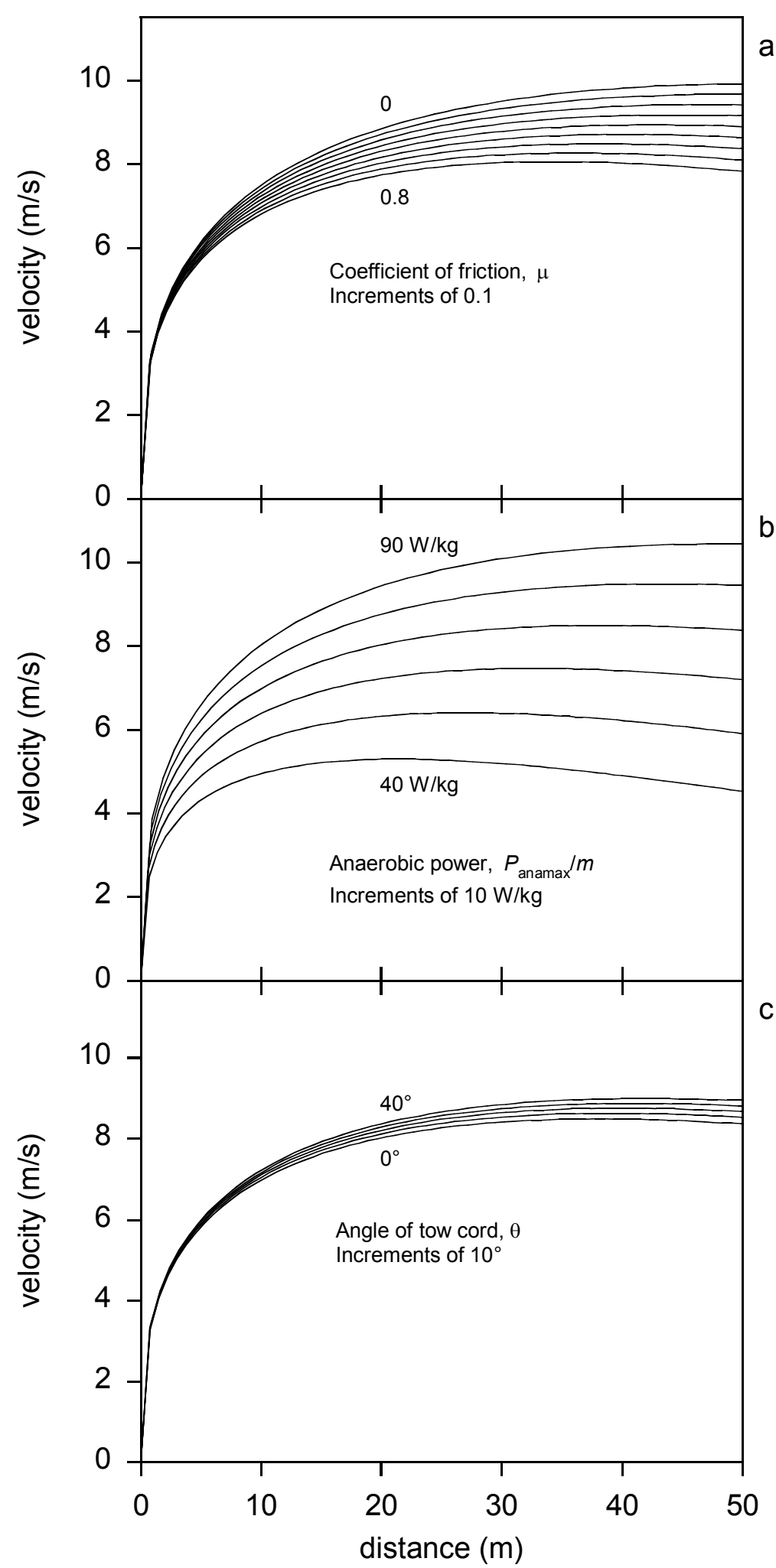

Fig. 3 These plots show the effects on an athlete's velocity profile (when towing a weighted sled) of: (a) the coefficient of friction of the running surface; (b) the athlete's anaerobic 
power; and (c) the angle of the tow cord to the horizontal. Calculations are for a standard athlete with $P_{\text {anamax }} / m=70 \mathrm{~W} / \mathrm{kg}, m=70 \mathrm{~kg}, m_{\mathrm{s}} / m=0.1, \mu=0.6$, and $\theta=0^{\circ}$ 


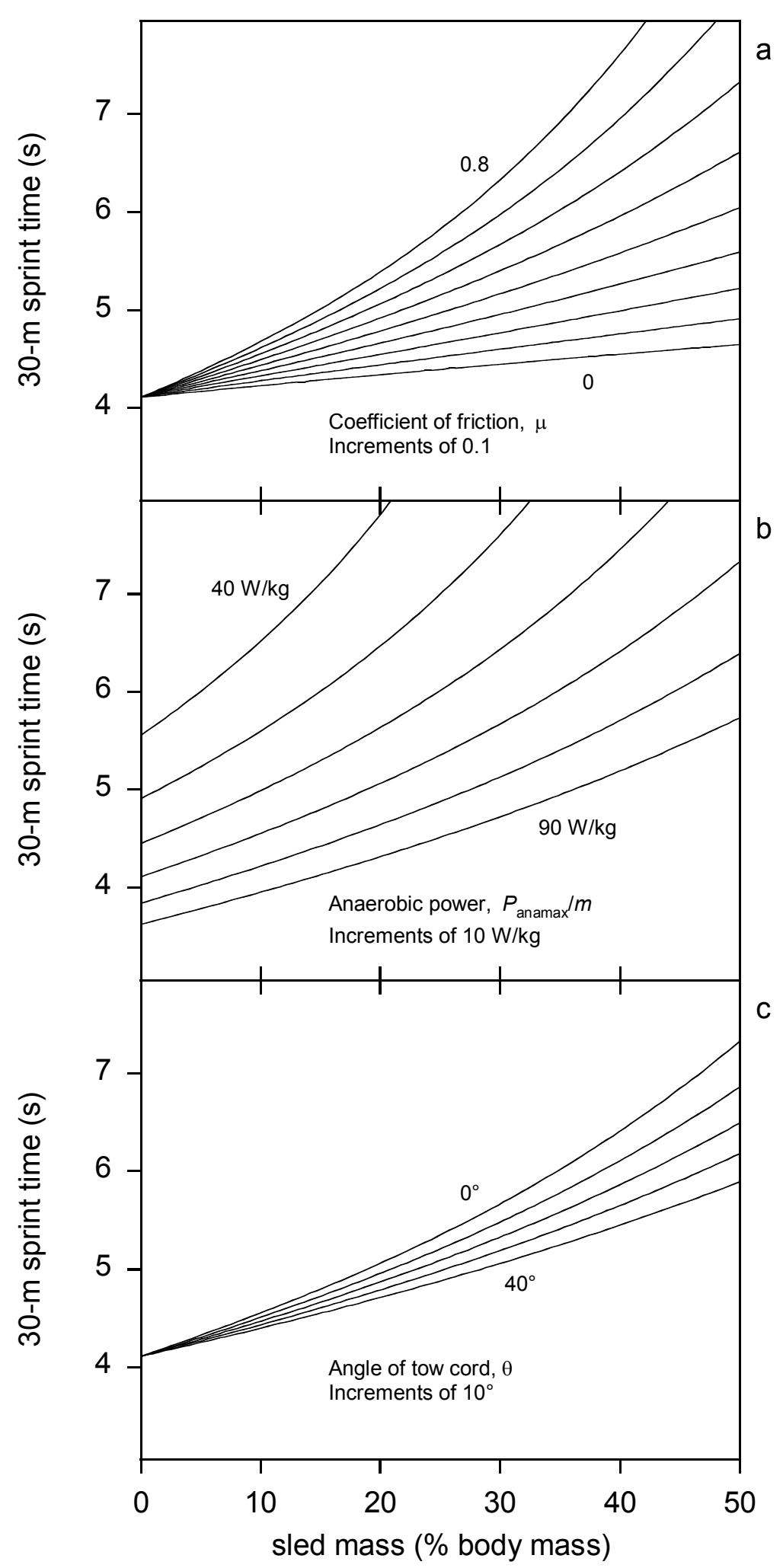

Fig. 4 These plots show the effects on an athlete's 30-m sprint time (when towing a weighted sled) of: (a) the coefficient of friction; (b) the athlete's anaerobic power; and (c) the angle of the tow cord. Calculations are for a standard athlete with $P_{\text {anamax }} / m=70 \mathrm{~W} / \mathrm{kg}, m=$ 
$70 \mathrm{~kg}, m_{\mathrm{s}} / m=0.1, \mu=0.6$, and $\theta=0^{\circ}$. These results show that when training on a running surface with a higher coefficient of friction the athlete must use a lighter sled so as to experience the same training load. Athletes with a greater normalised anaerobic power must use a heavier sled so as to experience the same training load. Also, it is not necessary to keep the angle of the tow cord constant because large changes in the angle do not substantially affect the athlete's velocity profile and sprint time 


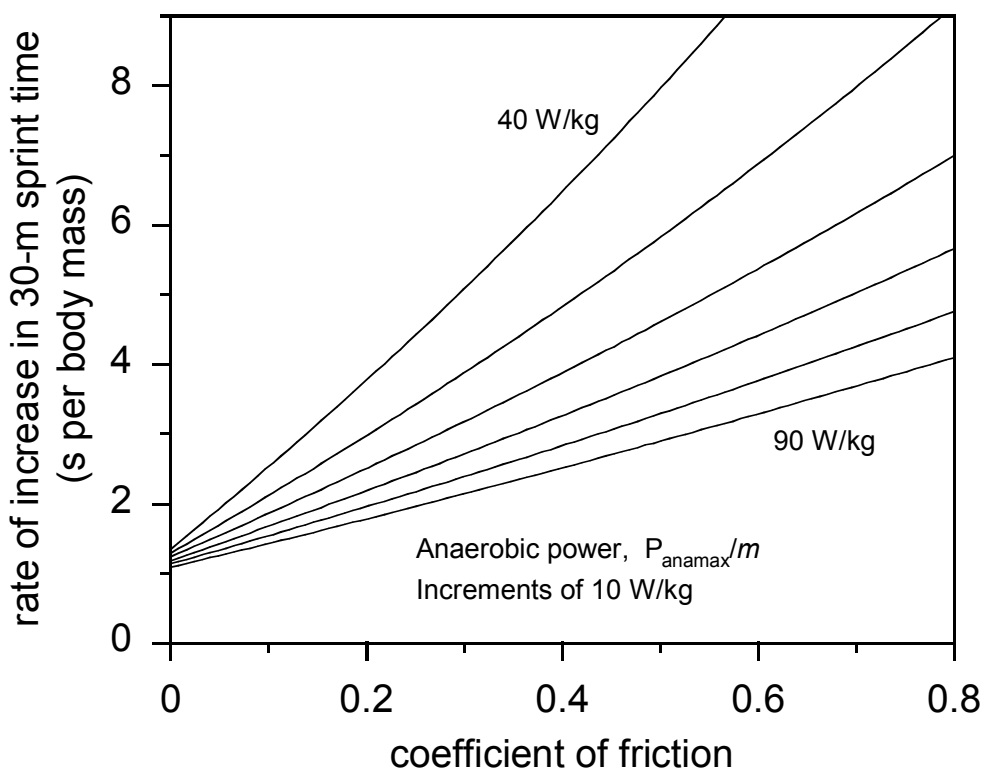

Fig. 5 This plot shows the effect of the coefficient of friction of the running surface $(\mu)$ on the rate of increase in 30-m sprint time (for a sled mass of less than about $10 \%$ of body mass). Calculations are for a standard athlete. These results indicate that we should expect to see greater inter-athlete differences in the rate of increase in sprint times on a running surface with a higher coefficient of friction 


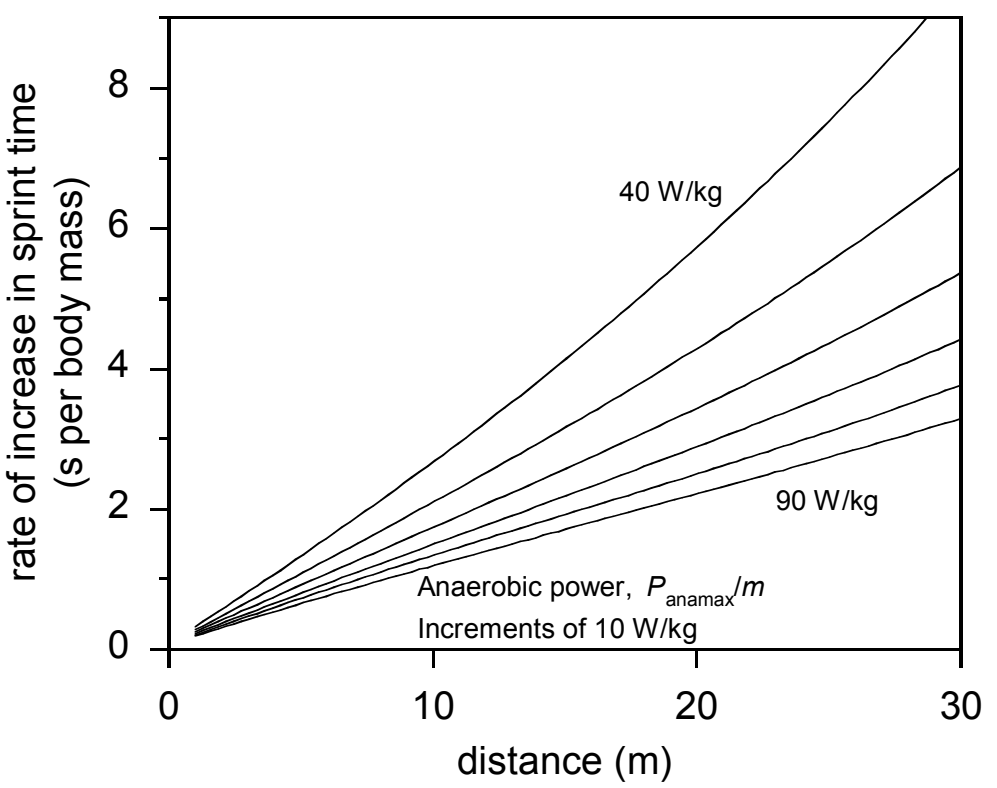

Fig. 6 This plot shows the effect of sprint distance on the rate of increase in sprint time (when the sled mass is less than about $10 \%$ of body mass). Calculations are for a standard athlete with $\mu=0.6$. These results indicate that we should expect to see greater inter-athlete differences in the rate of increase in sprint times when timing athletes over a longer distance 